\title{
Correlation of the Rates of Solvolysis of Methyl Fluoroformate Using the Extended Grunwald-Winstein Equation
}

\author{
Mi Hye Seong, Song Hee Choi, Yong-Woo Lee, Jin Bum Kyong,' Dong Kook Kim, and Dennis N. Kevill ${ }^{\dagger}$ \\ Deparment of Chemistry and Applied Chemistrv, Hanvang University. Ansan-si, Gveonggi-do 426-791, Korea \\ ${ }^{*}$ E-mail: jbhyongahanyang.ac.kr \\ ${ }^{\dagger}$ Department of Chemistrv and Biochemistrv, Northern Ihinois Chiversitw, DeKalb. Illinois 60115-2862, U. S. A. \\ Received July 5, 2009, Accepted September 5, 2009
}

\begin{abstract}
The specific rates of solvolysis of methyl fluorofonmate have been measured at $400^{\circ} \mathrm{C}$ in several hydroxylic solvents. Analy sis with the extended Grumwald-Winstein equation leads to sensitivities toward changes in solvent nucleophilicity $(h$ ) of $1.33 \pm 0.10$ and toward changes in solvent ionizing power $(\mathrm{m}) 0.73 \pm 0.06$. For methanolysis, a solvent deuteriun isotope effect of 3.98 is compatible with the incorporation of general-base catalysis into the substitution process. For four representative solvents, studies were made at several temperatures and activation parameters determined. These observations are also compared with those previously reported for alkyl halogenoformate esters and mechanistic conclusions are drawn.
\end{abstract}

Key Words: Methyl flıoroformate. Addition-elimination. Gnunwald-Winstein equation. Solvent isotope effect

\section{Introduction}

Chloroformate esters with primary alkyl groups are solvolyzed in most of the commonly studies solvents by an addition-elimination mechanism with the addition step being rate-determining. Only in solvents of very low micleophilicity and very high ionizing power is an ionization mechanism observed. For solvoly'ses of methyl chloroformate. ${ }^{1}$ the ionization mechanism was observed only in 1.1,1.3.3,3-hexafluoro2-propanol (HFIP)-water mixtures with at least 90\% HFIP content. The ionization range was larger for ethy $\mathrm{l}^{2}$ and $n$-propyl chloroformates, ${ }^{3}$ and ionization was indicated with up to $50 \%$ water content in $\mathrm{HFIP}-\mathrm{H}_{2} \mathrm{O}$ and with up to $10 \%$ water content in 2.2,2-trifluoroethanol (TFE)- water mixtures.

Although the solvoly'sis of alkyl halogenoformante esters for many years has been extensively studied kinetically, the kinetics and mechanism of alkyl fluorofomates have been studied less extensively than alkyl chloroformates. Alkyl halogenoformate esters are important reagents which are widely used in physiological and biological studies. ${ }^{45}$ A previously published study of the solvolysis of methyl chloroformate (MeOCOCl) ${ }^{l}$ is extended to methyl fluoroformate (MeOCOF). Alkyl halogenoformate esters reactions are commonly classified into two types. namely an ionization mechanism [eqn.

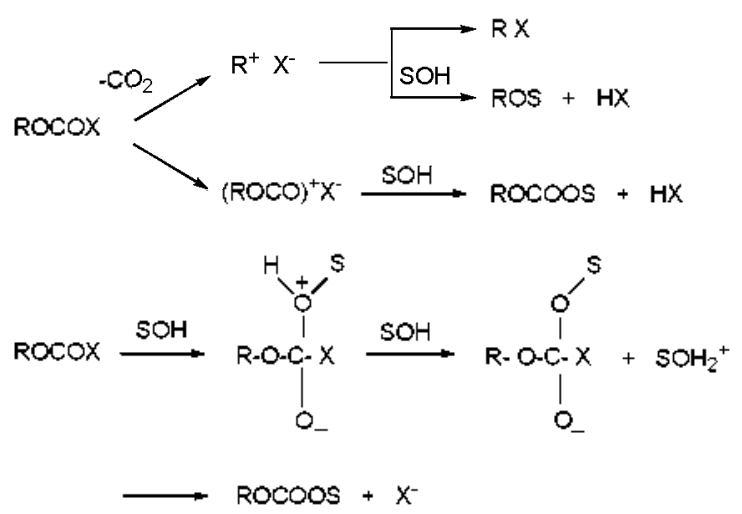

(1)] and an addition-elimination mechanism [eqn. (2)]. with addition being rate determining

The extended Grunwald-Winstein equation [eqn. (3)] has been applied to a powerful mechanistic tool for solvolysis reactions. ${ }^{6-9}$

$$
\log \left(k k_{0}\right)=N_{\mathrm{T}}-m I_{\mathrm{Cl}}-c
$$

In eqn. (3), $k$ and $k_{a}$ are the specific rates of solvolysis of a substrate in a given solvent and in $80 \%$ ethanol, respectively; $l$ is the sensitivity towards changes in $N_{\mathrm{T}}$, a scale of solvent nucleophilicity based on the specific rates of solvolysis of the $S$-methyldibenzothiophenium ion: and $m$ is the sensitivity towards changes in $\mathrm{I}_{\mathrm{Cl}}$. a scale of solvent ionizing power based on the specific rates of solvolysis of l-adamantyl chloride. Accordingly, the $l$ and $m$ values obtained are useful reference values for studies of the solvolyses of alkyl haloroformate esters.

The comparison of leaving group effects on the rates of solvoly sis of cluoroformate and fluoroformate esters has provided useful information about the reaction mechanism. Previous work concerning the solvolyses of $n$-octyl haloformates ${ }^{11}$ found the $\mathrm{k}_{\mathrm{F}} / \mathrm{k}_{[\mathrm{G}}$ ratio to be only slightly less than unity in $100 \%$ ethanol and $100 \%$ methanol, to be somewhat above unity for solvolyses in mixtures of water with ethanol acetone. dioxane. or TFE. These ratios were considered to be consistent with the addition step of an addition-elimination mechanism being rate determining.

In the present study, we report on the specific rates for solvoly'ses of methyl fluoroformate in a wide range of solvent type. Mechanistic conclusions are then drawn from a consideration of the analyses using the extended Grunwald-Winstein equation, including a comparison with the $l$ and $m$-values previously determined from kinetic studies of other haloformate esters. In addition to a detailed extended Grunwald-Winstein equation treatment of the specific rates, the influence of temperature on the specific rate (for four solvents) allows enthal- 
pies and entropies of activation to be calculated and a measurement in methanol- $d$ allows a determination of the solvent deuterium isotope effect. These analyses are also combined with a consideration of leaving-group effects to arrive at a reasonable mechanism.

\section{Results}

The specific rates of solvolysis of methyl fluoroformate at $40.0{ }^{\circ} \mathrm{C}$ are reported in Table 1 . The solvents consisted of ethanol. methanol, binary mixtures of water with ethanol. methanol 2,2.2-trifluoroethanol (TFE), acetone ( $\mathrm{Me}_{2} \mathrm{CO}$ ), and 1.1,1,3.3,3-hexafluoro-2-propanol (HFIP) and four binary mixtures of TFE and ethanol. The required $I_{T}$ and $I_{C l}$ values are also reported in Table 1 . A determination was also made in methanol- $d(\mathrm{MeOD})$. In methanol, ethanol, $80 \%$ ethanol, $70 \%$ acetone and $70 \%$ TFE specific rates of solvolysis of methyl fluoroformate (MeOCOF) and chloroformate (MeOCOCl) were determinied at two and three additional temperatures. and these values, together with calculated enthalpies and entropies of activation. are reported in Table 2 .

\section{Discussion}

The variance of $k_{F} \cdot k_{C l}$ ratios has suggested ${ }^{12}$ differences in mechanism and a useful additional probe will be to apply the extended Gnınwald-Winstein equation [eqn.(3)] and compare the $I$ and $m$ values with those previously obtained for alkyl fluoroformates.

Although some authors ${ }^{13.14}$ claim that leaving group effects
Table 1. Specific rates of solvolysis of methyl fluoroformate ${ }^{a}$ in pure and binary solvents at $40.0^{\circ} \mathrm{C}$ together with the appropriate solvent micleophilicity $\left(N_{\mathrm{T}}\right)$ and solvent ionizing power $\left(\boldsymbol{Y}_{\mathbf{a}}\right)$ values.

\begin{tabular}{|c|c|c|c|}
\hline Solvent $(\%)^{t}$ & $10^{-1} \mathrm{k}, \mathrm{s}^{-1}$ & $N_{\mathrm{T}}^{\mathrm{c}}$ & $Y_{\mathrm{C}}{ }^{l t}$ \\
\hline $100 \mathrm{MeOH}^{\circ}$ & $5.81 \pm 0.11$ & 0.17 & -1.17 \\
\hline $90 \mathrm{MeOH}$ & $52.6 \pm 0.6$ & -0.01 & -0.18 \\
\hline $100 \mathrm{EtOH}$ & $1.09 \pm 0.06$ & 0.37 & -2.52 \\
\hline $90 \mathrm{EtOH}$ & $19.6 \pm 1.0$ & 0.16 & -0.94 \\
\hline $80 \mathrm{EtOH}$ & $43.6 \pm 1.4$ & 0.00 & 0.00 \\
\hline $90 \mathrm{Me}_{2} \mathrm{CO}$ & $0.297 \pm 0.014$ & -0.35 & -2.39 \\
\hline $80 \mathrm{Me}_{2} \mathrm{CO}$ & $2.66 \pm 0.08$ & -0.37 & -0.83 \\
\hline $70 \mathrm{Me}_{2} \mathrm{CO}$ & $10.1 \pm 0.2$ & -0.42 & 0.17 \\
\hline $60 \mathrm{Me}_{2} \mathrm{CO}$ & $25.1 \pm 0.5$ & -0.52 & 0.95 \\
\hline $90 \mathrm{TFE}^{f}$ & $0.869 \pm 0.027$ & -2.55 & 2.85 \\
\hline $70 \mathrm{TFE}^{\prime}$ & $10.8 \pm 0.5$ & -1.98 & 2.96 \\
\hline $50 \mathrm{TFE}^{\prime}$ & $33.7 \pm 0.9$ & -1.73 & 3.16 \\
\hline $80 \mathrm{~T}-20 \mathrm{E}^{\mathrm{g}}$ & $0.283 \pm 0.053$ & -1.76 & 1.89 \\
\hline $60 \mathrm{~T}-40 \mathrm{E}^{2}$ & $1.06 \pm 0.04$ & -0.94 & 0.63 \\
\hline $40 \mathrm{~T}-60 \mathrm{E}^{2}$ & $1.95 \pm 0.01$ & -0.34 & -0.48 \\
\hline $20 \mathrm{~T}-80 \mathrm{E}^{\mathrm{g}}$ & $2.01 \pm 0.03$ & 0.08 & -1.42 \\
\hline $90 \mathrm{HFIP}^{\prime}$ & $0.590 \pm 0.032$ & -3.84 & 4.31 \\
\hline $50 \mathrm{HFIP}^{\prime}$ & $13.4 \pm 0.7$ & -2.49 & 3.80 \\
\hline \multicolumn{4}{|c|}{ 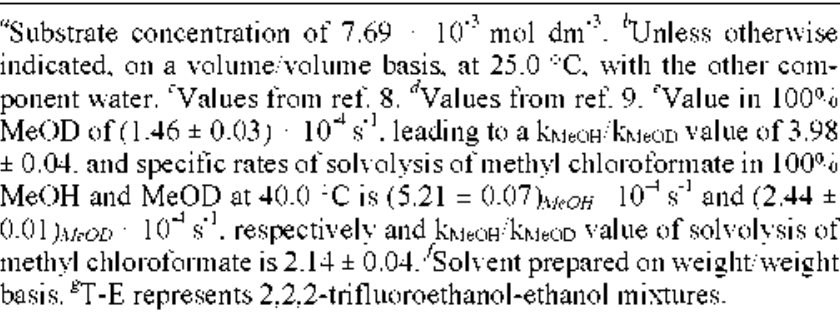 } \\
\hline
\end{tabular}

Table 2. Specific rates for solvoly sis of methyl fluoroformate (MeOCOF $)^{a}$ and methyl chloroformate (MeOCOCl) ${ }^{b}$ at various temperatures, and enthalpies $\left(\Delta H^{*}, \mathrm{kcal} \mathrm{mol}^{-1}\right)$ and entropies $\left(\Delta \mathrm{S}^{-3}, \mathrm{cal} \mathrm{mol}^{-1} \mathrm{~K}^{-1}\right)$ of activation at $40.0{ }^{\circ} \mathrm{C}$.

\begin{tabular}{|c|c|c|c|c|c|c|c|c|}
\hline \multirow{2}{*}{$\begin{array}{c}\text { Solvent } \\
(\%)\end{array}$} & \multirow{2}{*}{$\begin{array}{l}\text { Temp. } \\
\left({ }^{\circ} \mathrm{C}\right)\end{array}$} & \multicolumn{3}{|c|}{ MeOCOF } & \multirow{2}{*}{$\begin{array}{l}\text { Temp. } \\
\left({ }^{\circ} \mathrm{C}\right)\end{array}$} & \multicolumn{3}{|c|}{$\mathrm{MeOCOCl}$} \\
\hline & & $10^{4} k_{F}\left(\sec ^{-1}\right)$ & $\triangle H_{313.15^{d}}^{d}$ & $\Delta S^{\dot{x}}{ }_{313.15^{\prime \prime}}$ & & $10^{-1} k_{C I}\left(\mathrm{sec}^{-1}\right)$ & $\triangle H^{+}{ }_{313.15^{l}}$ & $\Delta S_{313.15^{d}}$ \\
\hline \multirow{4}{*}{$100 \mathrm{MeOH}$} & 25.0 & $2.47 \pm 0.04$ & $8.9 \pm 0.7$ & $-38.7 \pm 2.2$ & 35.0 & $3.49 \pm 0.04$ & $14.2 \pm 0.2$ & $-29.1 \pm 0.5$ \\
\hline & 30.0 & $3.26 \pm 0.09$ & & & 40.0 & $5.21 \pm 0.07^{\prime}$ & & \\
\hline & 35.0 & $4.70 \pm 0.23$ & & & 450 & $7.47 \pm 0.13$ & & \\
\hline & 40.0 & $5.81 \pm 0.11$ & & & 500 & $10.8 \pm 0.5$ & & \\
\hline \multirow[t]{4}{*}{$100 \mathrm{EtOH}$} & 25.0 & $0.424 \pm 0.019$ & $11.0 \pm 0.5$ & $-39.8 \pm 1.5$ & 350 & $0.895 \pm 0.001$ & $16.1 \pm 0.5$ & $-25.9 \pm 1.5$ \\
\hline & 30.0 & $0.573 \pm 0.017$ & & & 40.0 & $1.32 \pm 0.0 \mathrm{I}^{f}$ & & \\
\hline & 35.0 & $0.767 \pm 0.038$ & & & 45.0 & $2.05 \pm 0.02$ & & \\
\hline & 40.0 & $1.09 \pm 0.06$ & & & 500 & $3.16 \pm 009$ & & \\
\hline \multirow[t]{4}{*}{$80 \mathrm{EtOH}$} & 25.0 & $19.1 \pm 0.6$ & $9.1 \pm 1.2$ & $-38.9 \pm 3.9$ & 350 & $3.77 \pm 0.06$ & $13.5 \pm 0.4$ & $-31.2 \pm 1.1$ \\
\hline & 30.0 & $27.8 \pm 0.8$ & & & 40.0 & $5.27 \pm 0.03^{f}$ & & \\
\hline & 35.0 & $31.5 \pm 0.5$ & & & 45.0 & $7.79 \pm 0.09$ & & \\
\hline & 40.0 & $43.6 \pm 1.4$ & & & 50.0 & $10.9 \pm 0.1$ & & \\
\hline \multirow[t]{4}{*}{ 70 TFE } & 25.0 & $4.75 \pm 0.15$ & $9.9 \pm 1.2$ & $-39.0 \pm 3.9$ & 400 & $0.398 \pm 0.006^{f}$ & $18.5 \pm 0.8$ & $-20.7 \pm 2.6$ \\
\hline & 30.0 & $5.54 \pm 0.11$ & & & 45.0 & $0.668 \pm 0.006$ & & \\
\hline & 35.0 & $7.99 \pm 0.13$ & & & 50.0 & $1.03 \pm 0.03$ & & \\
\hline & 40.0 & $10.8 \pm 0.5$ & & & & & & \\
\hline \multirow[t]{3}{*}{70 Acetone } & 25.0 & $3.90 \pm 0.07$ & $11.1 \pm 0.2$ & $-35.0 \pm 0.7$ & & & & \\
\hline & $30.1^{2}$ & $5.52 \pm 0.17$ & & & & & & \\
\hline & 40.0 & $10.1 \pm 0.2$ & & & & & & \\
\hline
\end{tabular}

"Substrate concentration of $7.69 \cdot 10^{.3} \mathrm{~mol} \mathrm{dm}{ }^{-3}$. "Substrate concentration of $6.47 \quad 10^{-3} \mathrm{~mol} \mathrm{dm}^{-3}$. " $80^{\circ}$ o EtOH and $70^{\circ}$. acetone prepared on a volume : volume basis, at $25.0^{\circ} \mathrm{C}$ and $70^{\circ} \mathrm{i}$ TFE prepared on a weight weight basis. ${ }^{d}$ Witl assaciated standard error. ${ }^{\circ}$ Pretious value of $5.09=0.03 \quad 10^{-4}$ $\sec ^{-1}$ at 30.1 C from ref. $11 .{ }^{\prime}$ Values from ref. 1. 
in solvolytic reactions are not very sensitive to mechanistic changes. the consideration of these effects in nucleophilic substitution reactions has long been recognized as a useful tool in studying the reaction mechanism.

For $S_{\mathrm{N}} 1$ reaction, a value of $k_{F} / k_{C l}=10^{-6}-10^{-7}$ was observed in 4-(A.)-dimethylamino)benzoyl halide solvolyses ${ }^{16}$ and a low value of $k_{F} / k_{C l}=1.3 \times 10^{-1}$ was also observed for acetyl halide solvolyses in $75 \%$ acetone. ${ }^{15}$ These values reflect an appreciable ground-state stabilization for the fluoride ${ }^{17}$ and the need to break a strong carbon-fluorine bond in the rate determining step. In contrast. if the addition step is rate-determining. values of close to unity (and frequently above it). reflecting a large electron deficiency at the carbonyl carbon of a haloformate incorporating fluorine. ${ }^{18}$ are frequently observed.

This situation has recently been discussed in a consideration of $n$-octyl haloformate solvolyses, "where $k_{F} / k_{C l}$ specific rate ratios of 0.6 to 15 were observed. Similar ratios of $k_{F} \cdot k_{C l}$ specific rates have been observed previously for the solvolyses of other haloformate esters. ${ }^{101}=1$ For other haloformate esters. $k_{F} / k_{C l}$ ratios of 1.09 to 7.16 for solvolyses in $70 \%$ aqueous acetone at $30.1{ }^{\circ} \mathrm{C}$ have been reported. ${ }^{\mathrm{Il}}$

The leaving group specific rate ratios $\left(k_{F} / k_{C I}\right)$ determined in the present study for methyl haloformate are compared with the specific rate ratios for the same leaving groups observed in the bimolecular pathway of $n$-propyl, n-octyl. benzyl, and 1-adamantyl haloformates in various solvents (Table 3 ). ${ }^{i(1,2] \cdot 23}$ The specific rate ratios $\left(k_{F} / k_{C l}\right)$ for the solvolyses of methyl fluoroformate and chloroformate are similar to the values for all other the substrates but significantly larger than the analogous specific rate ratios for the partially solvolysis-decomposition reaction (ionization pathway) of 1 -adamantyl fluoroformate relative to the chloroformate in methanol. ethanol. and $80 \%$ ethanol. In these solvents. essentially all the reaction of 1-adamantyl chloroformate proceeds through the ionization pathway.

The solvent deuterium isotope effect value (footnote to Table 1) for methanolysis of methyl fluoroformate of $\mathrm{k}_{\mathrm{MecH}} /$ $\mathrm{k}_{\mathrm{X} \text { (e) }}=3.98 \pm 0.04$ at $40.0^{\circ} \mathrm{C}$ is of a magnitude usually taken to indicate that nucleophilic attack by a methanol molecule is assisted by general-base catalysis by a second methanol molecule. ${ }^{-4+-30}$ The solvent deuterium isotope effect value of

Table 3. The specific rate ratios $\left(k_{F} \cdot k_{C I}\right)$ of solvoly ses of alkvl haloformates in pure and binary solvents at various temperatures.

\begin{tabular}{lccccc}
\hline Solvent(\%) & methyl & n-propyl & n-octyl & benzyl & l-adamantyl \\
\hline $100 \mathrm{EtOH}$ & 0.83 & 0.57 & 0.62 & 1.19 & $1.31 \times 10^{-13}$ \\
$80 \mathrm{EtOH}$ & 8.28 & 5.62 & 8.09 & 11.5 & $1.25 \times 10^{-3}$ \\
$60 \mathrm{EtOH}$ & - & - & 15.1 & $14.6^{j}$ & - \\
$100 \mathrm{MeOH}$ & 1.12 & 0.75 & 0.95 & 1.78 & $5.91 \times 10^{-11}$ \\
$90 \mathrm{MeOH}$ & 5.11 & - & - & 7.18 & - \\
$80 \mathrm{Me} C \mathrm{CO}$ & 3.71 & $4.24^{\mathrm{g}}$ & 2.86 & 5.89 & - \\
$70 \mathrm{TFE}$ & 27.2 & 7.72 & $10.2^{\prime \prime}$ & 6.36 & - \\
\hline
\end{tabular}

${ }^{a}$ Unless otherwise indicated, on a volume volume basis, at $25.0^{\circ} \mathrm{C}$. with the other component water and $70^{\circ} .0$ TFE solvent prepared on weight: weight basis. ${ }^{b} \mathrm{At} 40.0 \mathrm{C}$ (this study). "At $40.0{ }^{\circ} \mathrm{C}={ }^{\circ}$ At $24.2 \mathrm{C}^{10}$ "At $25.0^{\circ} \mathrm{C} .{ }^{2}$ At $50.0 \mathrm{C}^{21}{ }^{8}$ For $70^{\circ} \mathrm{i}$ acetone. ${ }^{\mathrm{h}}$ For $80^{\circ} \mathrm{i}$ TFE. ${ }^{\mathrm{j}}$ For $70^{\circ} \mathrm{i}$ ethanol. methyl fluorofornate is ligher than for the methanolysis of methyl chloroformate $\left(\mathrm{k}_{\mathrm{M} \text { e } \mathrm{H} H} / \mathrm{k}_{\mathrm{MeOD}}=2.14 \pm 0.04\right.$ at $\left.40.0^{\circ} \mathrm{C}\right)$ or for the ethanolysis of a series of para-substituted phenyl chloroformates, where values in the range of $2.1 \sim 2.5$ were obtained. ${ }^{2}$ The higher value gives further support for the proposal that bond formation is more advanced at the transition state for addition to fluoroformates than for chloroformates.

For five solvents. the values of the enthalpy and the entropy of activation for the solvolysis of methyl fluoroformate are $8.9 \sim 11.1 \mathrm{kcal} / \mathrm{mol}$ and $-35.0 \sim-39.8 \mathrm{cal} / \mathrm{mol} \cdot \mathrm{K}$. and the values for the solvolysis of methyl cluloroformate are $13.5 \sim 18.5$ $\mathrm{kcal} / \mathrm{mol}$ and $-20.7 \sim-31.2 \mathrm{cal} / \mathrm{mol} \cdot \mathrm{K}$, respectively (Table 2). The very negative entropies of activation are consistent with the bimolecular nature of the proposed rate-determining step. While a bimolecular mechanism for the solvolyses is strongly indicated by the nuch slower reactions in TFE-rich solvents and by the appreciably negative entropies of activation. it is not established whether the process involves a stepw ise addition-elimination or a concerted $\left(\mathrm{S}_{\mathrm{N}} 2\right)$ pathway. A powerful test in considering detailed mechanisms of solvolysis is to carry out a correlation analy sis using the extended GrunwaldWinstein equation [eqn. (3)].

The specific rates of solvolysis of methyl fluoroformate were studies in a wide variety of pure and binary solvents. includeing the TFE- and HFIP-containing systems, which are important components of the extended Grumwald-Winstein correlations.

To see the effect of including fluoroalcohol-containing solvents and to avoid multicollinearity in the correlation of the specific rates of solvolysis of methyl fluorofomate, we have included 9 solvents with a fluoroalcohol (TFE or HFIP) component. As can be presented in Figure 1. there are appreciable deviations from the plot for the solvolytic data in TFE-ethanol mixtures with the largest deviations for the $80 \%$ TFE- $20 \%$ ethanol and $60 \%$ TFE-40\% ethanol points. Also in earlier

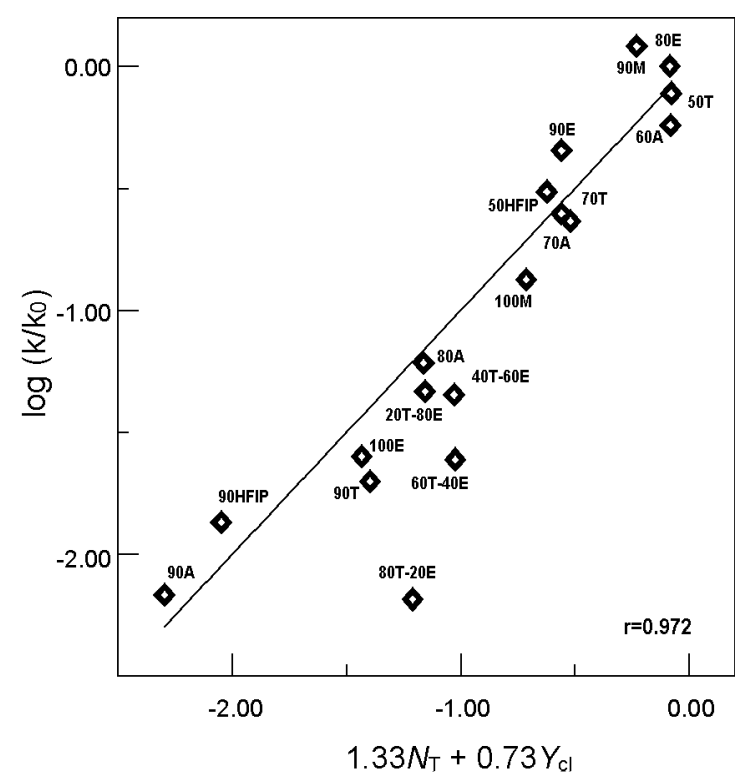

Figure 1. Plot of $\log \left(\mathrm{k} / \mathrm{k}_{0}\right)$ for solvolyses of methyl fluoroformate at $40.0^{\circ} \mathrm{C}$ against $\left(1.33 \mathrm{~N}_{\mathrm{T}}+0.73 \mathrm{Y}_{\mathrm{Cl}}\right)$. The data points for TFE-ethanol mixtures are not included in the correlation. 
Table 4. Correlation of the specific rates of solvolysis of methyl fluorofonate and a comparison with the corresponding values for the solvolyses of other fluoroformate esters using the extended Grunwald-Winstein equation.

\begin{tabular}{|c|c|c|c|c|c|c|c|}
\hline Substrate & Mech. ${ }^{a}$ & $\mathbf{n}^{b}$ & $l^{c}$ & $m^{c}$ & $c^{c}$ & $\mathrm{I}^{a}$ & $\mathrm{~lm}$ \\
\hline MeOCOF & $A-E$ & 18 & $1.39 \pm 0.19$ & $0.76 \pm 0.11$ & $-0.20 \pm 0.15$ & 0.880 & 1.84 \\
\hline $\mathrm{MeOCOF}$ & $A-E$ & $14^{e}$ & $1.33 \pm 0.09$ & $0.73 \pm 0.06$ & $-0.08 \pm 0.08$ & 0.972 & 1.82 \\
\hline $\mathrm{MeOCOCl}$ & $A-E$ & 19 & $1.59 \pm 0.09$ & $0.58 \pm 0.05$ & $0.16 \pm 0.07$ & 0.977 & 2.74 \\
\hline$n$-PrOCOF ${ }^{\prime}$ & $A-E$ & 19 & $1.80 \pm 0.17$ & $0.96 \pm 0.10$ & $-0.01 \pm 0.11$ & 0.940 & 1.88 \\
\hline$n-\mathrm{PrOCOCl}^{\kappa}$ & A-E & 22 & $1.57 \pm 0.12$ & $0.56 \pm 0.06$ & $0.15 \pm 0.08$ & 0.947 & 2.79 \\
\hline$n-\mathrm{PrOCOCl}^{z}$ & I & 6 & $0.40 \pm 0.12$ & $0.64 \pm 0.13$ & $-2.45 \pm 0.47$ & 0.942 & 0.63 \\
\hline$n$-OctOCOF ${ }^{3}$ & $A-E$ & $2 \hat{3}$ & $1.80 \pm 0.13$ & $0.79 \pm 0.06$ & $0.13 \pm 0.34$ & 0.959 & 2.28 \\
\hline $\mathrm{BzOCOF}^{s}$ & A-E & 16 & $1.57 \pm 0.20$ & $0.76 \pm 0.08$ & $-0.13 \pm 0.27$ & 0.933 & 2.07 \\
\hline $\mathrm{BzOCOCl}^{j}$ & A-E & 15 & $1.95 \pm 0.16$ & $0.57 \pm 0.05$ & $0.16 \pm 0.15$ & 0.966 & 3.42 \\
\hline $\mathrm{BzOCOCY}$ & I & 11 & $0.25 \pm 0.05$ & $0.66 \pm 0.06$ & $-2.05 \pm 0.11$ & 0.976 & 0.38 \\
\hline 1-AdOCOF & $A-E$ & 10 & $2.78 \pm 0.21$ & $1.01 \pm 0.06$ & $0.09 \pm 0.16$ & 0.987 & 2.78 \\
\hline 1-AdOCOF ${ }^{k}$ & I & 16 & -0 & $0.70 \pm 0.01$ & $-0.02 \pm 0.05$ & 0.999 & $\sim 0$ \\
\hline
\end{tabular}

${ }^{a}$ Addition-elinination (A-E) and ionization (I). "Number of solvent systems included in the correlation. "Using equation (3). with standard errors for $I$ and $m$ values and with the standard errors of the estimate accompanying the c values. "Correlation coeffient. "Onitting the four TFE-ethanol solvents. ${ }^{f}$ Values from ref. 22. ${ }^{8}$ Values trom ref. 3. "Values from ref. 10. 'Values from ref. 23. "Values from ref. 24. "Values from ref. 21.

correlations of other haloformate esters. it was found that the data points for these solvent systems usually lay below the correlation line.

Correlations were carried out both with and without the TFE-ethanol data. An analysis of the data using the extended Gnınwald-Winstein equation to the specific rates of solvolysis of methyl fluoroformate leads to a poor linear correlation with values of $1.39 \pm 0.19$ for $l .0 .76 \pm 0.11$ for $m,-0.20 \pm 0.15$ for $c$. and 0.880 for the correlation coefficient ( $\mathrm{r}$ ). Recalculation with omission of the four data points in TFE-ethanol mixtures led to values of $1.33 \pm 0.10$ for $l, 0.73 \pm 0.06$ for $m .-0.08 \pm$ 0.08 for $\mathrm{c}$, and 0.972 for the correlation coefficient. When the TFE-ethanol points are omitted from the correlation. the $/$ and $m$ values are only slightly reduced but a considerably improved value for correlation coefficient $(0.972$ relative to 0.880$)$ is observed. The results of the correlation are reported in Table 4. together with the corresponding parameters obtained in the analy ses of earlier studied substrates. The higher $m$-values for the solvolyses of fluoroformates. relative to chloroformates. may reflect the kinetically favorable influence of increased solvation of the developing negative charge on the carbonyl oxygen in the presence of the more electronegative fluorine attached at the carbonyl carbon.

The $l \mathrm{~m}$ ratio has been suggested as a useful mechanistic criterion and the values of Table 4 divide nicely into two classes with values of 1.8 to 3.4 for those entries postulated to represent addition-elimination (A-E) and 0.38 to 0.63 for those believed to represent ionization (I).

The $/$ and $m$ values of methyl fluoroformate in Table + are very similar to those for the earlier studied substrates ( $n$-propyl-n-octyl-, and benzyl fluoroformates), which have been shown to solvolyze with the addition step of an additionelimination pathway being rate determining.

To prove further the similarity between solvent effects upon the specific rates of solvolysis of methyl- and n-octyl fluoroformates, we have carried out a direct comparison of the log $\left(\mathrm{k} / \mathrm{k}_{\mathrm{o}}\right)$ values for methyl fluoroformate against those for $n$-octyl fluoroformate for the 15 solvents for which data in available for both substrates. A good linear plot was obtained, with a slope of $0.90 \pm 0.07$. intercept of $0.12 \pm 0.10$. and correlation coefficient of 0.963

\section{Conclusions}

The solvolyses of methyl fluoroformate give a satisfactory extended Grunwald-Winstein correlation [eqn. (3)] over wide range of $\hat{H}_{\mathrm{T}}$ and $Y_{\mathrm{Cl}}$ values. The sensitivities to changes in $\mathrm{H}_{\mathrm{T}}$ and $Y_{G l}(l=1.33$ and $m=0.73)$ are very similar to those for the several fluoroformate esters (Table 4). which are shown to solvolyze with the addition step of an association-dissociation (addition-elimination) pathway being rate deternining.

The $\mathrm{k}_{\mathrm{F}} / \mathrm{k}_{\mathrm{Cl}}$ values obtained in a comparison with the corresponding solvolysis of methyl chloroformate are very sinular to those for solvolyses of n-octyl fluoroformate. consistent with a bimolecular addition-elimination mechanism, proceeding through a tetrahedral intermediate.

The solvent deuterium isotope effect value for methanoly sis $\left(\mathrm{k}_{\mathrm{Me} \mathrm{iH}} / \mathrm{k}_{\mathrm{Men}} \mathrm{iD}\right)$ of 3.98 is of a magnitude usually taken to indicate that mucleophilic attack by a methanol molecule is assisted by general-base catalysis by a second methanol molecule.

The entropies of activation $(-35.0 \sim-39.8 \mathrm{cal} / \mathrm{mol} \cdot \mathrm{K})$ for ethyl fluoroformate solvoly ses believed to involve rate-determining attack at acyl carbon are considerably more negative than the values for solvoly ses believed to proceed by the ionization pathway (the entropies of activation are for l-adantantyl chloroformate $+3.3 \sim+6.7 \mathrm{cal} / \mathrm{mol} \cdot \mathrm{K}^{20}$ and for I-adamantyl fluoroformate $-8.0 \sim-14.7 \mathrm{cal} / \mathrm{mol} \cdot \mathrm{K}^{21}$ ). The more negative entropy of activation values for the methyl fluoroformate reaction are consistent with the bimolecular nature of the rate-deternining step.

In the present study the solvoly'ses of methyl fluoroformate have a pathway involving bimolecular attack by solvent at acyl carbon, by what is suggested to be the addition step of an addition-elimination pathway being rate determining [eqn. (2)]. 


\section{Experimental}

The methyl chloroformate (Aldrich) was purified by fractional distillation at reduced pressure. The methyl chloroformate $(47.5 \mathrm{~g} .0 .500 \mathrm{~mol}$ ) was syringed into a three-neck flask (200 $\mathrm{mL}$ ) containing dried $\mathrm{KF}(35.0 \mathrm{~g}, 0.600 \mathrm{~mol})$ and 18-crown-6 $(4.77 \mathrm{~g} .0 .0180 \mathrm{~mol})$ and fitted with a Teflon stirring bar, a condenser topped by an Ar gas inlet, a septum cap, and a ground glass stopper. as described earlier. ${ }^{312}$ The mixture then was stirred efficiently at room temperature until FT-IR (Bio-Rad FTS 6000) analysis of an aliquot indicated that no chloroformate remained $\left(\mathrm{C}=\mathrm{O}\right.$ stretch at $1777 \mathrm{~cm}^{-1}$. fluoroformate $\mathrm{C}=\mathrm{O}$ stretch at $1839 \mathrm{~cm}^{-1}$ ). After a reaction time of 7 days the product fluoroformate was isolated directly from the reaction apparatus by simple distillation at a reaction temperature of $41-42^{\circ} \mathrm{C}$ (lit ${ }^{31} 39 \cdot 40^{\circ} \mathrm{C}$ ).

Solvents were purified as previously described. ${ }^{* 2}$ The kinetic procedures were as described earlier, ${ }^{31, ? 2}$ using a substrate concentration of about $7.69 \times 10^{-3} \mathrm{~mol} \mathrm{dm}{ }^{-3}$ or $6.47 \times 10^{-3} \mathrm{~mol}$ $\mathrm{dm}^{-3}$. and with $5 \mathrm{~mL}$ aliquots removed for titration. The $/$ and $m$ values were calculated using multiple regression analysis.

\section{References}

1. Kevill, D. N.; Kin, J. C.: Kyong, J. B. J. Chem. Res. Symop. 1999,150

2. Kevill, D. N.; D'Souza, M. T. J. Org. Chem. 1998, 63, 2120 .

3. Kyong, T. B.; Won, H.; Kevill, D. N. Iht J.Mhol Sci. 2005, 6, 87.

4. Villas-Boas, S. G.; Delicado, D. G.; Akesson, M.: Nielson, T. Anal Biochem. 2003, 322, 134

5. Biemann, U.; Metzger, T. O.J.Am. Chem. Soc. 2004, 126, 10319 .

6. Grunwald, E.: Winstein, S.: Tones, H. W. J. Am Chem. Soc. $1951,73,2700$.

7. Schadt, F. L.: Bentley, T. W.; Schlever, P. V. R. J. Am. Chen. Soc. $1976,98,7667$.

8. Kevill, D. N. In advances in Otrantitative Stmctrre-Properts Relationships, Vol. 1; Charton, M., Ed.; JAI Press: Greenwich,
CT, 1996; pp 81

9. Bentley, T. W.: Llewellyn, G. Prog. Phus. Org. Chem. 1990, 17 , 121

10. Kevill, D. N.; D Souza, M. J. J. Chem. Soc., Pewin Trans. 2 2002, 240.

11. Queen, A: Nour, T. A.J. Chem. Soc., Pewin Trans. 2 1976, 935.

12. Kevill, D. N. In The Chemisty of the Functional Groups: The Chemistry of Act Halides; Patai, S., Ed:- Wiley: New York, 1972: Chapter 12.

13. Harris, T. M.; Shafer, S. G.; Moffatt, J. R.; Becker, A. R. J. Am. Chem. Soc. 1979, 101, 3295.

14. Bentley, T. W.; Bowen, C. T.: Parker, W.: Watt, C. I. F. J. Chem. Soc, Perkin Trans. $21980,1244$.

15. Swain, C. G.; Scott, C. B. J. Am. Chem. Soc. 1953, 75, 246.

16. Song, B. D. Tencks, W. P. J. Am. Chent. Soc. 1989, 111, 8470 .

17. Wiberg, K. B.; Rablen, P. R. J. Org. Chem. 1998, 63, 3722.

18. Kevill, D. N.: D'Souza, M. I. J. Org. Chem. 2004, 69, 7044.

19. Kyong, T. B.: Kim, Y. G.; Kim, D. K.; Kevill, D. N. Bull. Korean Chem. Soc. 2000, 21, 662.

20. Kevill, D. N.; Kyong, T. B.; Weitl, F. L. J. Org. Chent 1990, 55 , 4304 .

21. Kevill, D. N.: Kyong, J. B. J. Ong. Chem 1992, 57, 258.

22. Seong, M. H; Kyong, T. B.; Kim, D. K; Kevill, D. N. Bull. Korean Chem. Soc. 2008. 29. 1747.

23. Kyong, J. B.; Ryu, S. H.; Kevill, D. N. Int. J. Mol. Sci. 2006, 7 , 186.

24. Kyong, J. B.: Park, B. C.; Kim, C. B.; Kevill, D. N. J. Org. Chem. 2000, 65, 8051

25. Ryu. Z. H.: Shin. S. H.: Lee. T. P.: Lim. G. T.: Bentley, T. W. J. Chem. Soc. Pethin Trans. 2 2002, 1283.

26. Oh, Y. H.; Tang, G. G.; Lim, G. T: Ryu, Z. H. Bull. Konean Chem. Soc. 2002, 23, 1083.

27. Yew, K. H; Koh, H. J; Lee, H. W.; Lee, I. J. Chent. Soc. Perkin Trans. 2 1995, 2263.

28. Koo, I. S.: Yang, K.; Kang, K.: Lee. I. Bull Korean Chem. Soc. 1998, 19,968.

29. Kevill, D. N.: Miller, B. J. Org. Chem. 2002, 67, 7399.

30. Lee, S. H.; Rhu, C. J.; Kyong. I. B.; Kim, D. K.; Kevill, D. N. Bull. Korean Chem. Soc 2007, $28,657$.

31. Olah, G. A. J. Oig. Chem. 1979, $\$ 4,3872$ 